\title{
Incentivizing Peer Review
}

\author{
Ann Blair Kennedy, LMT, BCTMB, DrPH, \\ Executive Editor, IJTMB
}

\author{
Department of Biomedical Sciences, Division of Behavioral, Social, and Population \\ Health, University of South Carolina School of Medicine Greenville, Greenville, SC, USA
}

Since the 1700s, peer review has been a part of scientific publication. Quality peer reviews take extensive time and effort yet reviewers are not often compensated. This editorial announces the new offering of the National Certification Board for Thereputic Massage \& Bodywork (NCBTMB)approved continuing education hours for our peer reviewers who complete timely reviews. Instructions to register as a peer reviewer and how to conduct a review are offered. Thank you to our 2016 and 2017 peer reviewers.

Peer review, having experts in the field evaluate the work of colleagues, has been a mainstay in scientific publication since the 1700 s. ${ }^{(1)}$ Quality peer review takes time and allows reviewers to be on the fore-front of science. ${ }^{(2)}$ Yet, often peer reviewers are not thanked or compensated for their work. With this editorial, we at the International Journal of Therapeutic Massage and Bodywork (IJTMB), hope to remedy that situation.

The Journal will now provide three research continuing education hours to our peer reviewers upon completion of their reviews. Other journals have offered access to their journal or a database of journals as an incentive; ${ }^{(3)}$ since the IJTMB is an open access journal, that does not work. Instead, we have collaborated with the Massage Therapy Foundation and the National Certification Board for Therapeutic Massage and Bodywork to offer three Research Continuing Education (3 CEs) hours for each peer-reviewed manuscript. To qualify to receive the CEs, reviewers must accept the offer to review, the reviews must be submitted within the allotted timeframe (usually 2-3 weeks), and the review must be complete with clear and constructive suggestions. In addition, we also ask that reviewers, in their comments to the authors, to state their comments and suggestions for revision in such a way that it would not demoralize the author of the manuscript or make them not want to provide revisions and/ or submit to the IJTMB in the future. We have also simplified our peer review form to try to capture all the necessary information and still try to reduce the burden for reviewers.
Those who are interested in becoming a peer reviewer can sign up when subscribing to the Journal or within the "Profile" section (Figure 1). When signing up to become a reviewer, please include reviewing interests and areas of expertise (in box indicated by green arrow in Figure 1). This will help the editors find appropriate individuals for the articles which have been submitted. We need not only those with expertise in research, but also massage therapy practitioners to be peer reviewers. It should be noted, however, that reviewers are selected based on their credentials, experience in massage therapy, background in research methodology, and familiarity of the technique in the manuscript.

New reviewers may want some guidance on how to provide a complete peer review. Lovejoy, Revenson, and France provide an excellent primer on reviewing ${ }^{(2)}$ and Wiley Author Services offers a clear step by step guide (https://authorservices.wiley. $\mathrm{com} /$ Reviewers/journal-reviewers/how-to-performa-peer-review/step-by-step-guide-to-reviewing-amanuscript.html) on how to review a manuscript, which may be of interest to some of our readers. At the IJTMB, we hope that the addition of offering CEs to peer reviewers will provide an inducement for new and current peer reviewers to produce high-quality and timely reviews.

\section{THANK OUR PEER REVIEWERS FROM 2016-2017}

We would like to thank all our peer reviewers who participated in offering their viewpoints on manuscripts in 2016 and into the summer of 2017 when this editorial was written. Thank you!

Katie Adams

Craig Atkinson

Derek Austin

John Balletto

Amanda Baskwill

Anita Boser

Jerrilyn Cambron 


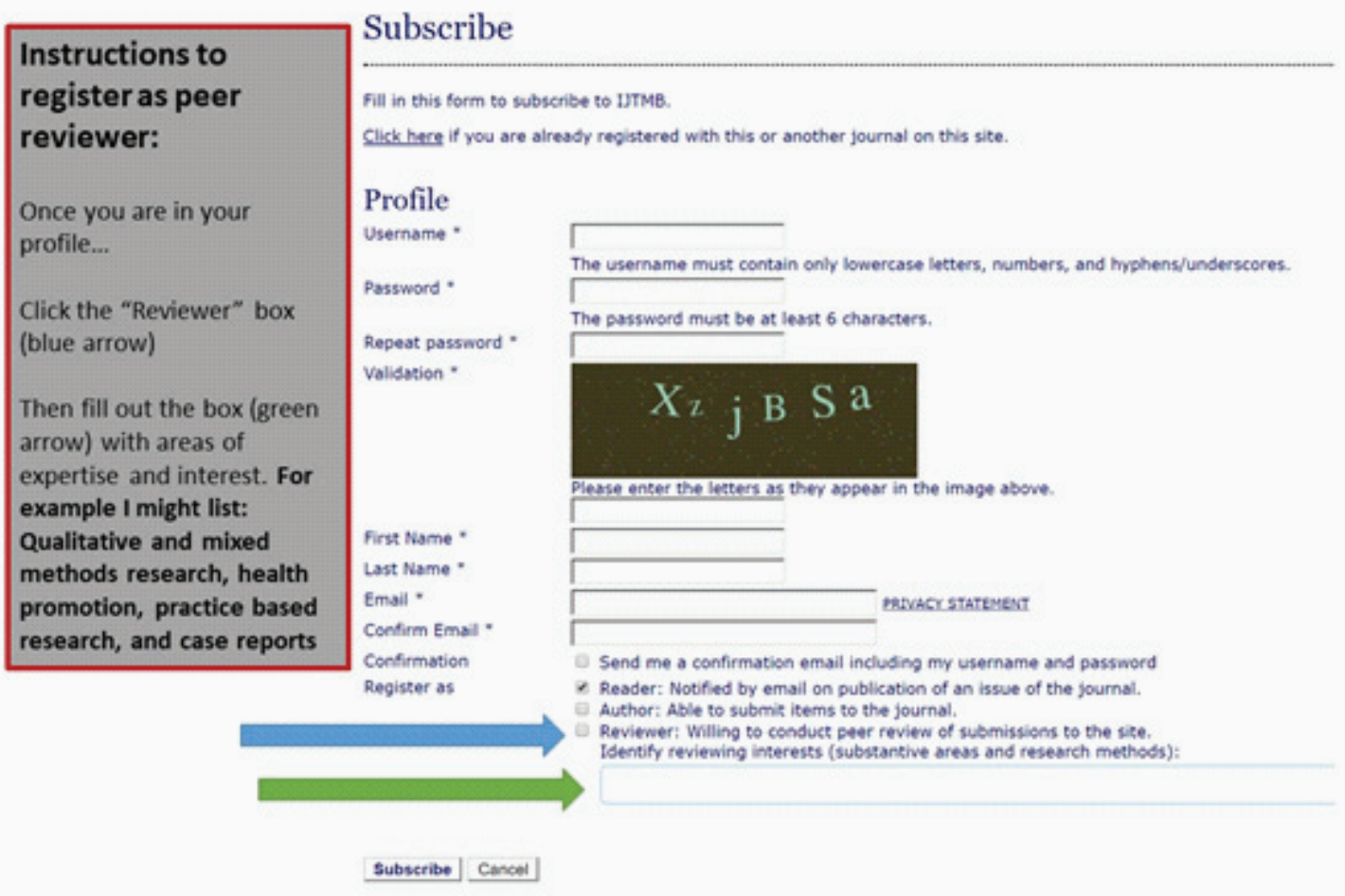

FIGURE 1. A screenshot of the subscription page for the IJTMB. The blue arrow indicates reviewer box to check to become a peer reviewer for the IJTMB; the green arrow indicates box for listing areas of expertise.

\author{
Gregory Casey \\ Rosemary Chunco \\ Samantha Colliton \\ Andre Farasyn \\ Luann Fortune \\ Sandy Fritz \\ Donelda Gowan-Moody \\ Elliot Greene \\ Kimberly Griffith \\ Alicia Hopkins \\ Glenn Hymel, EdD, LMT \\ Brent Jackson \\ Younes Jahangiri Noudeh \\ Steve Jurch \\ Ania Kania-Richmond \\ Christy Kollath-Cattano \\ William Meeker \\ Martha Menard \\ Lisa Mertz \\ Jeff Moggach \\ Felicity Molloy \\ Albert Moraska, PhD \\ Niki Munk, LMT, PhD \\ April Neufeld \\ Caitlin Notley \\ Nathan O'Hara \\ Giovanni Ottoboni \\ P. Darlene Peters \\ Antony Porcino
}

Susan Prasch

Grant Rich

Gilbert Rivera

Conar Rochford

Michaela Schenkelberg

JoEllen Sefton

Amanda Shand

Penny Shumaker Jeffrey

Matthew Stewart

Robin Thomas

Diana Thompson

Alexander van de Water

Matthew van der Giessen

Ruth Werner

Marc White

John Winslow

\section{COPYRIGHT}

Published under the CreativeCommons AttributionNonCommercial-NoDerivs 3.0 License.

\section{REFERENCES}

1. Suls J, Martin R. The air we breathe: a critical look at practices and alternatives in the peer-review process. Perspect Psychol Sci. 2009;4(1):40-50. 
2. Lovejoy TI, Revenson TA, France CR. Reviewing manuscripts for peer-review journals: a primer for novice and seasoned reviewers. Ann Behav Med. 2011;42(1):1-13.

3. Gasparyan AY, Gerasimov AN, Voronov AA, Kitas GD. Rewarding peer reviewers: maintaining the integrity of science communication. J Korean Med Sci. 2015;30(4):360-364.
Corresponding author: Ann Blair Kennedy, LMT, BCTMB, DrPH, University of South Carolina School of Medicine Greenville, Department of Biomedical Sciences, Division of Behavioral, Social, and Population Health, 701 Grove Road, Greenville, SC 29605, U.S.A. E-mail: Kenneda5@greenvillemed.sc.edu 